\title{
Natural Clays as Potential Amino Acids Carriers for Animal Nutrition Application
}

\author{
Cinzia Cristiani ${ }^{1, *(1)}$, Elisabetta Finocchio ${ }^{2, *}$, Luciana Rossi ${ }^{3, *(1)}$, Carlotta Giromini ${ }^{3}\left(\mathbb{D}\right.$, Matteo Dell'Anno ${ }^{3}(\mathbb{0}$, \\ Sara Panseri ${ }^{3}$ and Maurizio Bellotto ${ }^{4}(\mathbb{D}$
}

check for updates

Citation: Cristiani, C.; Finocchio, E.; Rossi, L.; Giromini, C.; Dell'Anno, M.; Panseri, S.; Bellotto, M. Natural Clays as Potential Amino Acids Carriers for Animal Nutrition Application. Appl. Sci. 2021, 11, 5669. https://doi.org/ 10.3390/app11125669

Academic Editor: Daniel Cozzolino

Received: 16 May 2021

Accepted: 14 June 2021

Published: 18 June 2021

Publisher's Note: MDPI stays neutral with regard to jurisdictional claims in published maps and institutional affiliations.

Copyright: (c) 2021 by the authors. Licensee MDPI, Basel, Switzerland. This article is an open access article distributed under the terms and conditions of the Creative Commons Attribution (CC BY) license (https:// creativecommons.org/licenses/by/ $4.0 /)$.
1 Politecnico di Milano, CMIC—Dipartimento di Chimica, Materiali e Ingegneria Chimica "G. Natta", Piazza L. da Vinci 32, 20133 Milano, Italy

2 Dipartimento di Ingegneria Civile, Chimica e Ambientale, Università di Genova, Via all'Opera Pia 15, 16145 Genova, Italy

3 VESPA-Dipartimento di Scienze Veterinarie per la Salute, la Produzione Animale e la Sicurezza Alimentare, Università degli Studi di Milano, Via dell'Università 6, 26900 Lodi, Italy; carlotta.giromini@unimi.it (C.G.); matteo.dellanno@unimi.it (M.D.); sara.panseri@unimi.it (S.P.)

4 Opigeo S.r.l., Via dell'Industria, 6, 36047 Montegalda, Italy; maurizio.bellotto@opigeo.eu

* Correspondence: cinzia.cristiani@polimi.it (C.C.); elisabetta.finocchio@unige.it (E.F.); luciana.rossi@unimi.it (L.R.)

Featured Application: This work aims to study innovative natural clays as bioactive molecules carriers for animal nutrition application.

\begin{abstract}
This study has the main purpose of testing natural carriers as more sustainable alternatives to polymeric coating. New clay-based hybrid organic-inorganic materials have been prepared. An innovative procedure for the intercalation of the bioactive molecule is proposed. The synthesis process implies the use of mild operating conditions and does not require the use of organic reactants or solvents. Moreover, the use of natural carriers, and milder environmentally friendly process conditions, fulfill the requirement of a mostly safe, greener production. The capture and the release properties of the final material mainly depend on the carrier morphology. Large zeolite content in the mineral clays can favor the capture of very large methionine loadings, but due to the trapping mechanism, typical of these structures, zeolites prevent a satisfactory release in mild condition and physiological condition. The Freundlich adsorption model has been found to be able to predict the capture behavior. Once the proper carrier is selected, the preparation procedure guarantees the protection of the amino acid in the right form. Neither the structure of the inorganic matrix nor the amino acid structure was changed in the preparation process. Methionine was detected in its zwitterionic form, showing the main IR bands only slightly affected by the interaction. Further studies on methionine bioaccessibility and intestinal absorption from methionine-Adsorbene (MET-ADS) are required to optimize the application of natural clay in in-field animal nutrition.
\end{abstract}

Keywords: amino acid protection; feed; mineral clay; intercalation; methionine; FTIR spectroscopy; bioaccessibility

\section{Introduction}

Over the past few decades, the precision nutrition of animal farming has developed more detailed tools and technologies to pursue the distribution and balance of essential nutrients in an effective animal diet. The final target is to fulfill more comprehensive and dynamic nutritional recommendations in order to improve both the animals' health and the quality of products of animal origin [1]. In this context, the efficient use of dietary proteins and protein digestibility play a pivotal role [2]; moreover, this approach satisfies sustainability and nutritional ecology principles. Indeed, the tendency to reduce crude protein (CP) levels in an animal diet is in the direction of nitrogen minimization in animal excretion, an increasing environmental issue [3,4]. 
The need for an increased supplementation of synthetic essential amino acids in animal feeding is a crucial point. Among essential amino acids, methionine plays a key role, being related to methyl donation in protein synthesis, and involved in antioxidant and immune defense processes. For this reason, methionine is heavily used in animal feed, to improve their health status and growth performance. In high-yielding dairy cows, methionine is one of the most limiting amino acids, while it is the second most limiting amino acid in a typical swine diet. Therefore, an efficient methionine supplementation can improve the dietary protein utilization, when dietary methionine is limiting [5].

Protected dietary amino acids have been proposed to prevent their degradation by the rumen microbiota and along the gastrointestinal tract, and to guarantee a higher bioaccessibility and bioavailability.

A variety of approaches have been experimented to reduce the degradation of essential amino acids during the gastrointestinal transit; in particular, one of the most applied approaches implies the delivery of the protected molecules or the use of a bioequivalent chemical analogue [6]. Until now, such a protection is guaranteed by means of expensive biodegradable polymeric coating, able to resist at the physiological $\mathrm{pH}$. For example, a larger concentration of blood plasma methionine was reported in the case of a rumenprotected methionine form, where a methionine core was coated with a $\mathrm{pH}$-sensitive copolymer (styrene and 2-methyl-5-vinylpyridine) [7]; or, an alternative, where methionine was microencapsulated in a lipid matrix of carnauba wax by a melt-emulsification process [8]. Despite the interesting results, these methionine protection methods were confined to ruminants, and/or required quite a complex protection technology. Moreover, in this protection process, the use of moderately high temperatures and organic chemicals are required, which implies cost and possible risk of the amino acid degradation.

In this respect, the use of natural carriers and milder, environmentally friendly process conditions should be preferred.

Regarding carriers, it is undeniable that clay minerals could represent good candidates, in view of their sorption capacity $[9,10]$. Among others, both sodium and calcium pelleted bentonites have been used as a feed supplement for many years. As a matter of fact, bentonite is used in feed applications for its good absorption capability of pathogenic microorganisms, enzymes, toxins, mycotoxins, and heavy metal ions from feeds. Bentonite's high adsorption capacity has been related to particle size, shape, and to the high specific surface area [5-9].

Other clay minerals, such as kaolinite, palygorskite, etc., have been reported as effective for feed application. Indeed, due to their adsorbent properties, clay minerals are most suitable for the treatment of gastrointestinal disturbances, particularly diarrhea. Despite some concerns about clay minerals' nonselective binding interaction, which could result in the depletion of other important components of the diets, clay-based feed additives have been increasingly incorporated into animal diets to prevent adverse animal health conditions [11]. The positive effects of dietary supplementation with clays, such as, for instance, the evidence of improved weight gain and feed conversion in pigs, can counteract the reported negative effects [12].

In these last years, growing attention has also been paid to the use of incorporated biological molecules and structural peptides in clay-based synthetic materials, not necessarily for feed application. The advantage is related to the synergic combination of the physical properties of the biological part and the synthetic domains [13]. For this purpose, among other biomolecules, $\alpha$-amino acids have been the most considered by synthetic organic chemists, because they are cheap and readily available optically pure. The use of these compounds in natural or synthetic polymer-based hybrid materials increases the biocompatibility of these systems. In this respect, examples are bioresorbable sutures, screws or plates, tissue engineering scaffolds, and drug delivery systems. Such nanohybrid materials can combine the structural and textural properties of the inorganic host with the functionality of the organic guest. For this application, the smectite group, including montmorillonite (MMT), is reported as the best choice, in view of its swelling capability 
and the cationic exchange capacity. For example, Na-Cloisite has been modified with L-alanine, L-valine, L-leucine, L-isoleucine, L-phenylalanine, and L-methionine by a cation exchange method to synthetize improved organoclays, greener and more environmentally friendly [13].

Na-Cloisite has also been reported as the matrix of choice to synthesize novel optically active organo-modified layered materials, by reaction of protonated L-methionine and the mineral clay through ion exchange [14].

The production of an optimized polymer-based nanocomposite, based on the methionine-montmorillonite system, has been described and discussed in the literature. The presence of the intercalated amino acid in the mineral nanoclay increased the clay dispersibility in the polymer matrix, thus improving the mechanical properties of the polymeric materials [15].

Moreover, the use of montmorillonite, modified with protonated L-methionine via a cation exchange process, has been proposed for fast and efficient adsorption of amoxicillin from aqueous solutions. The improved clay spacing has been reported to facilitate the amoxicillin adsorption process, and an enhanced adsorption capacity has been reported for the modified montmorillonite, compared to the pristine clay [16].

Finally, the clay-methionine system has also been reported recently for the effective adsorption of lead ions in aqueous solutions. A methionine-montmorillonite composite was successfully fabricated by L-methionine mixed with Na-montmorillonite. The improved adsorption capacity of the composite was correlated to the carbonyl oxygen atom of methionine which, due to the lone pair of electrons, is able to complex $\mathrm{Pb}^{2+}$ ions [17].

Despite the studies reported above on the use of mineral clays for adsorption purposes, or on the use of methionine-clay system for synthetic purposes, nothing, to the authors' knowledge, has been reported on the use of bentonite as carrier for methionine protection and for methionine-controlled delivery in feed applications. Moreover, nothing is reported about the intercalation process of methionine in its neutral form.

In the past, the possibility to intercalate organic molecules, without ion exchange, in montmorillonite natural clays has been investigated. Polyethylene-glycols (PEG), characterized by different molecular weight 1500 and 4000, as well as (PA), characterized by different length and structures, representative of large organic molecules, were intercalated without exchange in two different standard Ca- and Na-montmorillonite mineral clays. The main operating parameters (i.e., temperature, reaction time, solution concentrations) for a successful intercalation of the molecules were set up; in addition, the microstructural characterization of the synthesized organoclays was assessed by XRD, FTIR, and TG-DTA [18-22].

On the bases of the previous experiences, the protection of methionine, in its neutral form, via intercalation in a clay mineral is here proposed, with the main purpose of testing natural carriers as more sustainable alternatives to polymeric coating. The novelty of this paper is set in this context, and intends to propose and demonstrate the possibility to prepare an innovative natural nanoclay-based material containing the bioactive molecule intercalated in its neutral form via a simple, low-cost, and greener process. Moreover, on the bases of the physicochemical characterization and the bioadsorption tests, the paper intends to give guidelines for the selection of the most proper carrier, this point being considered of paramount importance for the final application.

For this purpose, new hybrid methionine-clay materials were prepared in aqueous environment, at room temperature and without the use of organic chemicals and organic solvents. Different natural carriers, namely a commercial bentonite (Adsorbene), a montmorillonite (Veegum K), and a zeolite (BioKi) were considered and compared. The obtained materials were characterized by several analytical techniques to investigate the composition and the physical properties of the final material. Intercalation, without ion exchange, was performed to evaluate the adsorption capability of the different carriers towards methionine. Synthesis parameters, such as methionine concentration and $\mathrm{pH}$, were also 
set up. Moreover, the gastrointestinal stability and bioaccessibility of methionine within methionine-Adsorbene product (MET-ADS) was also assessed to optimize its use in feed.

\section{Materials and Methods}

\subsection{Materials}

Methionine, $\mathrm{C}_{5} \mathrm{H}_{11} \mathrm{NO}_{2} \mathrm{~S}$, (supplied by Istituto delle Vitamine S.P.A., Segrate MI, (Italy) purity $>98.7 \%$, MET in the following), involved in tissue growth, milk production, and in supporting liver and immune system functions, was chosen as target molecule, since it can be representative of all essential amino acids.

The natural commercial clays, Adsorbene ${ }^{\circledR}$ (Biomicron S.R.L., Torino TO, (Italy) ADS in the following), commonly used in feed industries for the adsorption of aflatoxins, genotoxic, and cancerogenic mycotoxins produced by Aspergillus, was selected as methionine carrier in view of its high adsorption capability. Moreover, the commercial natural zeolite BioKi $^{\circledR}$ (Antika Officina Botanika S.R.L., Collecorvino PE, (Italy), BIO in the following), and Veegum $\mathrm{K}^{\circledR}$, a pure natural smectite widely used in pharmaceutical and cosmetic applications (supplied by Vanderbilt Minerals, LLC., Gouverneur, NY 13642, (USA), VEG in the following) were considered for comparison. These commercial clays are not pure products; therefore, they have been fully characterized. Results are reported in the following.

Pure $\mathrm{HNO}_{3}, \mathrm{NaOH}$ (both by Aldrich, St. Louis, Missuri (USA), 98\% pure), and distilled water were also used.

\subsection{Intercalation Procedure}

The final hybrid organoclay material was prepared according to the procedure sketched in Figure 1, which allows for intercalation of neutral organic molecules without ion exchange [23,24]. Both single and multiple intercalation experiments were applied.

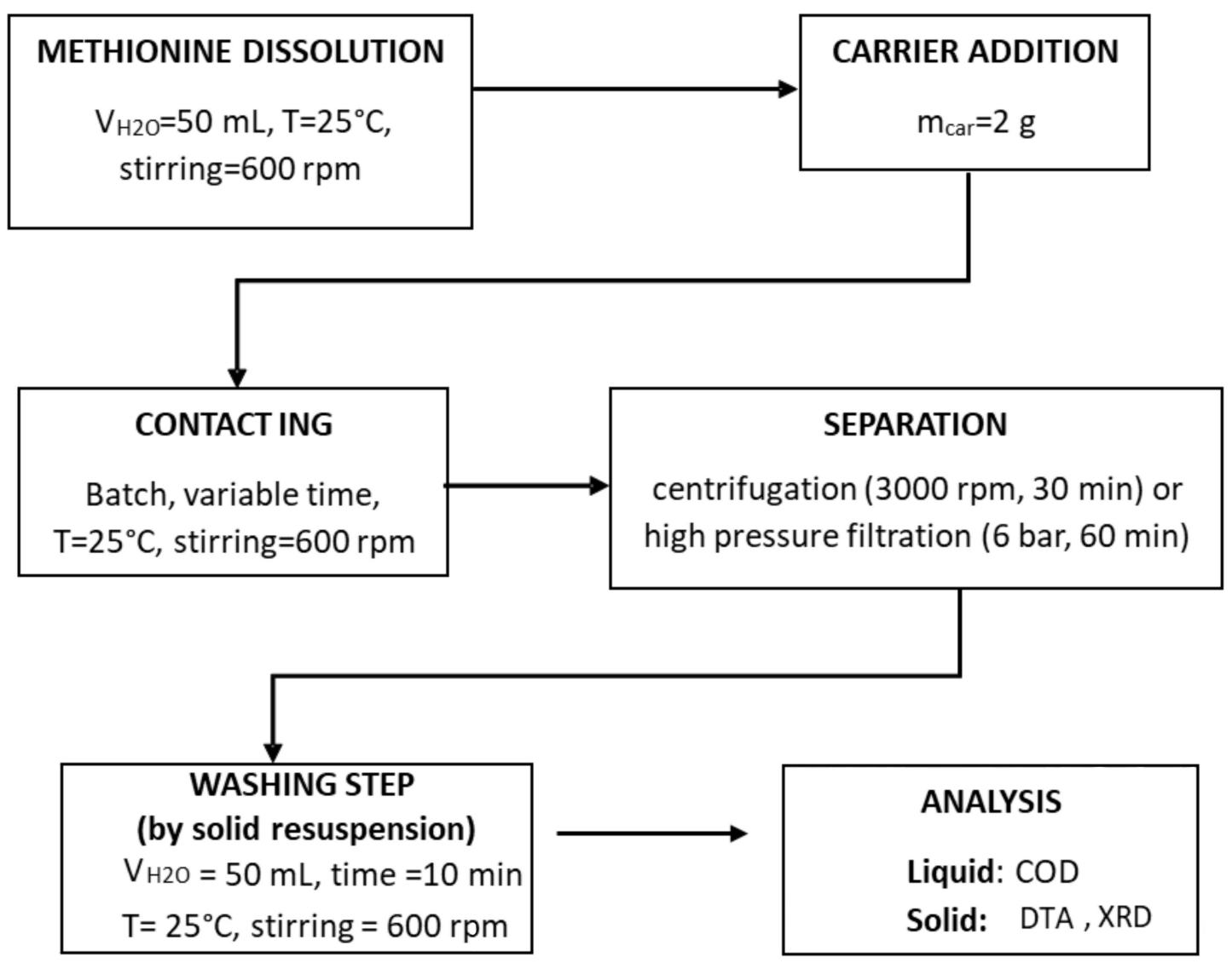

Figure 1. Flowchart of the single intercalation step. 
During the experiments, solution pH was monitored by a Mettler Toledo FE20/EL20 digital pH-meter (Mettler Toledo, Milano, MI, Italy).

Single step-The single-step experiment was performed using all three commercial carriers.

In the typical single-step intercalation experiment, a certain amount of methionine, depending on the desired final concentration, was dissolved in $50 \mathrm{~mL}$ of demineralized water. The dissolution occurred in a few minutes at $25^{\circ} \mathrm{C}$, by magnetic stirring at $600 \mathrm{rpm}$.

Then, $2 \mathrm{~g}$ of the carriers were added to the prepared solution, and the obtained suspension was stirred at $600 \mathrm{rpm}$ and $25^{\circ} \mathrm{C}$ for $30 \mathrm{~min}$, in order to reach the equilibrium. Finally, solid-liquid separation was carried out by centrifugation at $3000 \mathrm{rpm}$ for $30 \mathrm{~min}$ (by a 32 RotoFix centrifuge, Hettich Italia, Milano MI, (Italy)).

Multiple step-The multiple-step experiments consisted of the repetition, for a given number of steps, of the single-step process. Upon a rapid redispersion of the alreadyintercalated solid in distilled water $\left(10 \mathrm{~min}, 25^{\circ} \mathrm{C}\right.$, stirring rate $\left.600 \mathrm{rpm}\right)$, and separation by centrifugation, the solid was recontacted with $50 \mathrm{~mL}$ of a methionine solution, applying the same experimental conditions: methionine concentration of the previous single step, stirring $30 \mathrm{~min}$ at $600 \mathrm{rpm}$ and $25^{\circ} \mathrm{C}$. After the liquid-solid separation by centrifugation at $3000 \mathrm{rpm}$ for $30 \mathrm{~min}$, the liquid and the solid were analyzed as usual.

Washing step - Selected samples, after capture, were washed twice by subsequent resuspensions of the powders in $50 \mathrm{~mL}$ of demineralized water for $10 \mathrm{~min}$ at $25^{\circ} \mathrm{C}$, stirring rate at $600 \mathrm{rpm}$. After solid-liquid separation as usual, the methionine in the supernatant solution was analyzed.

\subsection{Characterization}

Intercalated methionine was quantified by chemical oxygen demand (COD); such analysis was demonstrated to be correct and reliable for the quantification of organic molecules intercalated in mineral clays [23]. COD analyses were performed by a Spectrodirect Lovibond Instrument, 2021 Tintometer GmbH, (www.lovibond.com, Germany), according to standard procedures [ASTM D1252-06].

A total of $1 \mathrm{~mL}$ of supernatant solution was diluted in $50 \mathrm{~mL}$ of distilled water, and the COD analysis was performed by oxidation of the sample in pure air at $150{ }^{\circ} \mathrm{C}$ for $120 \mathrm{~min}$. The analyses were performed on all the supernatant liquids and on the initial contacting solutions. Intercalated methionine was determined according to Equation (1):

$$
\text { Intercalated MET }(\mathrm{g}) \text { = Initial MET }(\mathrm{g}) \text { - Supernatant MET }(\mathrm{g})
$$

where: "Initial MET" and "Supernatant" are, respectively, the amount of methionine in the initial and supernatant liquid separated upon centrifugation, both determined by COD analysis.

Difference in the intercalation/adsorption characteristics and mechanisms between the different substrates were assessed by adsorption isotherms. Both Langmuir and Freundlich models were considered and compared according to literature [25].

Solids were analyzed by different physicochemical analysis:

- $\quad$ Laser Granulometry (dispersion in water, CILAS 715 Granulometer, Odelzhausen I (Germany)).

- $\quad$ BET analysis (N2 as analysis adsorptive, bath temperature $77.35 \mathrm{~K}$ ), while porosity of the material was determined by $\mathrm{Hg}$ intrusion by means of Autopore V9600 (Micromeritics Instrument Corporation, Norcross, GA, USA). Samples before analysis were degassed overnight at $60^{\circ} \mathrm{C}$.

- $\quad$ X-ray powder diffraction (XRD) patterns were recorded with a Bruker D8 Advance diffractometer using a graphite-monochromated $\mathrm{Cu} \mathrm{K} \alpha$ radiation, $2 \theta$ range 10-80, step scan $0.02^{\circ} 2 \theta$ and 1 s per step.

- $\quad$ Thermal analyses (TG-DTG) were performed with a DTA-TG SEIKO 6300 thermal analyzer (Riga, (Latvia)) flowing air, temperature range of $25-1000{ }^{\circ} \mathrm{C}$, and heating rate $10^{\circ} \mathrm{C} / \mathrm{min}$. 
- $\quad$ FTIR spectra were recorded in the 4000-400 $\mathrm{cm}-1$ range by an FTIR Thermo Nicolet Nexus (Thermo Electron Corporation, Madison, WI, USA) spectrometer equipped with a DTGS KBr detector. FTIR skeletal analyses of inorganic matrix and the related modified materials were performed on $\mathrm{KBr}$ pressed disks, prepared by mixing the solid sample with $\mathrm{KBr}$ powder in an agate mortar (about $1 \% \mathrm{w} / \mathrm{w}$ concentration of powders). Measurements of composite skeletal spectra were repeated twice, 100 scans each, resolution $4 \mathrm{~cm}-1$, background air, in the mid-IR range, i.e., $4000-400 \mathrm{~cm}-1$. In another set of experiments, self-supporting disks of pure pressed powders (about $30 \mathrm{mg}$ weight, $1 \mathrm{~cm} 2$ ) were placed in the sample holder in the cell connected to a conventional gas manipulation apparatus in order to investigate the thermal evolution of surface and gas phase species in static conditions. FTIR analyses were carried out in order to characterize the clay matrix and to evaluate the interactions occurring between the target molecules and the host material [26].

\subsection{MET-ADS In Vitro Digestion Simulation}

MET-ADS in vitro digestion was performed according to the method of Minekus et al. [27] and further adapted by Giromini et al. [28] and Miralles et al. [29]. Briefly, $20 \mathrm{~g}$ of METADS were mixed with $150 \mathrm{~mL}$ of distilled $\mathrm{H}_{2} \mathrm{O}$ and maintained on an orbital shaker at $150 \mathrm{rpm}$ for $5 \mathrm{~min}$. The digestion procedure involved three phases. For the oral phase, $6.66 \mathrm{mg}$ of $\alpha$-amylase in $2.1 \mathrm{~mL}$ of $1 \mathrm{mM} \mathrm{CaCl}_{2}, \mathrm{pH} \mathrm{7}$, was added to the samples, and they were incubated for $30 \mathrm{~min}$ at $37^{\circ} \mathrm{C}$ on a shaker. For the gastric phase, the $\mathrm{pH}$ was decreased to 3 with $6 \mathrm{M} \mathrm{HCl}$, and $0.9 \mathrm{~g}$ of pepsin in $8.3 \mathrm{~mL}$ of $0.1 \mathrm{M} \mathrm{HCl}$ was added. The samples were then incubated for $120 \mathrm{~min}$ at $37^{\circ} \mathrm{C}$ on a shaker. For the small intestinal phase, the $\mathrm{pH}$ was increased to 7 with $6 \mathrm{M} \mathrm{NaOH}$, and $0.2 \mathrm{mg}$ of pancreatin and $1.2 \mathrm{~g}$ of bile in $\mathrm{NaHCO}_{3} 0.5 \mathrm{M}$ were added to the samples before the final incubation of $180 \mathrm{~min}$ at $37^{\circ} \mathrm{C}$ on a shaker. A blank sample (digestive enzymes alone), a positive control, and a negative control were included as reference samples, and for stability, tests in all digestions were performed $(n=3)$. Quantification of methionine release after in vitro digestion was performed by Q-Exactive Orbitrap high-resolution mass spectrometry (HPIEC-HRMSOrbitrap; Thermo Scientific, San Jose, CA, USA) analysis according to the method described by Panseri et al. [30]. Typically, CTR, MET-ADS, and MET samples were thawed rapidly at $20{ }^{\circ} \mathrm{C}$. Briefly, after membrane filtration $(0.45 \mu \mathrm{m}, \mathrm{PVDF}), 3,4,5$-trimethoxycinnamic acid $(100 \mathrm{mg} / \mathrm{L}$ in methanol) was added to an aliquot of $50 \mu \mathrm{L}$ and the samples were injected. The temperatures of capillary and of vaporizer were set at $330^{\circ} \mathrm{C}$ and $280{ }^{\circ} \mathrm{C}$. The electrospray voltage operating in negative mode was adjusted at $3.50 \mathrm{kV}$.

\section{Results}

\subsection{Carriers Characterization}

Mineral clays were fully characterized by XRD (Supporting S1), granulometry (Supporting S2), and morphological analysis. Results are summarized in Table 1.

As reported above, among others, Adsorbene ${ }^{\circledR}$ (ADS, in the following) was selected as possible carrier, in view of its sorption capability and its common use in feed application. Therefore, it was fully characterized (Table 1). It is evident that ADS is a complex mixture of different mineral clays and zeolites. With such a composition, the result is a reasonably high surface area $\left(93 \mathrm{~m}^{2} / \mathrm{g}\right)$, which makes it a good methionine carrier candidate.

Such a complex phase composition could make it difficult to understand the behavior of the material during intercalation and also not allow establishment of a direct correlation between the adsorption and the interaction with the carrier. This information is of paramount importance to understand the behavior of the MET-carrier system in the final application. Therefore, other two mineral clays, namely Veegum $\mathrm{K}^{\circledR}$ (VEG in the following), i.e., a pure expandable montmorillonite, and $\mathrm{BioKi}^{\circledR}$ (BIO, in the following), i.e., a fully zeolite-based material, were selected for comparison, and fully characterized, also (Table 1). ADS and BIO were characterized by very close surface area, pore volume, 
and pore diameter. Due to this close similarity, it can be assumed that ADS morphology is predominantly due to the zeolite components.

Table 1. Phase composition and morphological characteristics of the considered mineral clays.

\begin{tabular}{|c|c|c|c|c|c|}
\hline Mineral Clay & Phase Composition (XRD) & $\begin{array}{c}\text { Surface Area } \\
{\left[\mathrm{m}^{2} / \mathrm{g}\right]}\end{array}$ & $\begin{array}{l}\text { Pore Volume } \\
\qquad\left[\mathrm{cm}^{3} / \mathrm{g}\right]\end{array}$ & $\begin{array}{l}\text { Pore Diameter } \\
\text { [nm] }\end{array}$ & $\begin{array}{c}\text { Particle } \\
\text { Dimensions }[\mu \mathrm{m}]\end{array}$ \\
\hline Adsorbene & $\begin{array}{l}\text { Chabazite (PDF card 01-085-1046), } \\
\text { Phillipsite (PDF card 01-072-4634), } \\
\text { Bentonite (PDF card 00-003-0015), } \\
\text { Illite (PDF card 01-075-0948) }\end{array}$ & 93 & 0.09 & 4 & $0.3,5,20,50$ \\
\hline BioKi & $\begin{array}{l}\text { Chabazite (PDF card 01-085-1046), } \\
\text { Phillipsite (PDF card 01-072-4634), } \\
\text { Illite (PDF card 01-075-0948), } \\
\text { Hydrosodalite (PDF card } \\
\text { 01-073-5304), Albite (PDF card } \\
\text { 19-1184) }\end{array}$ & 103 & 0.08 & 3 & $0.3,5,20,60,110$ \\
\hline Veegum K & Montmorillonite & 50 & 0.11 & 9 & $2,5,10$ \\
\hline
\end{tabular}

Similar characterization was performed by FTIR. The spectrum of pristine ADS clay is characterized by the broad and complex absorption in the $1200-900 \mathrm{~cm}^{-1}$ region, consistent with vibrational modes due to the presence of $\mathrm{SiO}$ in the structure. The zeolite fraction detected in this material is also characterized by weak peaks in the low-frequency region due to $\mathrm{SiO}$ deformation modes, and structural $\mathrm{OH}$ bending. Other minor features overlapping in this region can be assigned to oxide impurities. In the high-frequency region of the spectrum, a band due to structural $\mathrm{OH}$ groups are detected centered at $3620 \mathrm{~cm}^{-1}$, partially masked by the broad absorption due to vibration modes of adsorbed molecular water (Supporting S3). The strong band at $1450 \mathrm{~cm}^{-1}$, with very weak signals around $2900 \mathrm{~cm}^{-1}$, associated to $\mathrm{CH}$ bending, was probably due to the presence of some organic compounds, such as tetramethylammonium (TMA) [31]. This compound and its derivates are reported to be used to expand the clay interlayer to increase the adsorption capability of the carrier [32,33]. These molecules are so strongly bonded to the clay that they should not be released during utilization. The skeletal spectrum of BIO shows the same main features assigned to $\mathrm{SiO}$ vibrational modes, that is, a broad band centered at $1030 \mathrm{~cm}^{-1}$ and assigned to structural $\mathrm{SiO}$ stretching modes, and weaker bands at lower frequencies due to deformation modes. The Veegum spectrum shows a main split band at $1036 \mathrm{~cm}^{-1}$, due to structural $\mathrm{SiO}$ vibrations, and features in the range $950-500 \mathrm{~cm}^{-1}$ related to the presence of $\mathrm{AlO}$ and $\mathrm{MgO}$ components. In the high frequency region, a broad absorption centered at $3450 \mathrm{~cm}^{-1}$ is due to $\mathrm{OH}$ stretching of adsorbed water [31-34].

As already remarked, it has been demonstrated that the adopted experimental procedures allow for the intercalation of an organic molecule without ion exchange [24], and this approach was proven on a variety of substances with different chemical natures and structures [18-23]. This procedure guarantees that the properties of the intercalated molecule (e.g., methionine) are thus preserved until it reaches the absorption site. It was also reported that the operating parameters, such as contact time, $\mathrm{pH}$, and solution concentrations, were fundamental for the setting up and the success of the reaction. In particular, contact time may influence adsorption equilibria, while $\mathrm{pH}$ may control the nature of the intercalating molecule, for instance, via protonation or deprotonation mechanism [14,15]. Therefore, these parameter effects were fully investigated; results are reported and analyzed in the following paragraphs.

\subsection{Effect of Intercalation Operating Parameters: Contact Time and $p H$ Solution}

Considering that $\mathrm{pH}$ is a fundamental parameter which can influence the uptake, the $\mathrm{pH}$ values of solutions containing pure methionine in the concentration range $0.0201-0.2000 \mathrm{M}$ were first analyzed. All the measured $\mathrm{pH}$ values were between 5.22 and 5.61; therefore, it 
can be assumed that $\mathrm{pH}$ is constant (the average $\mathrm{pH}$ value is 5.4) within the methionine concentration range experimented in this study (Supporting S4).

In order to set the best conditions for the intercalation reaction on the Adsorbene substrate, two operating parameters were considered, i.e., contact time and $\mathrm{pH}$ of the methionine solution. Therefore, for an experimental campaign considering two sets of intercalation tests, both at fixed methionine concentration $(0.2 \mathrm{M})$, one was performed at different contact time, namely in the range 10-360 min, while the second was performed at $\mathrm{pH}$ range 1-8. Results are reported in Figure 2a,b.
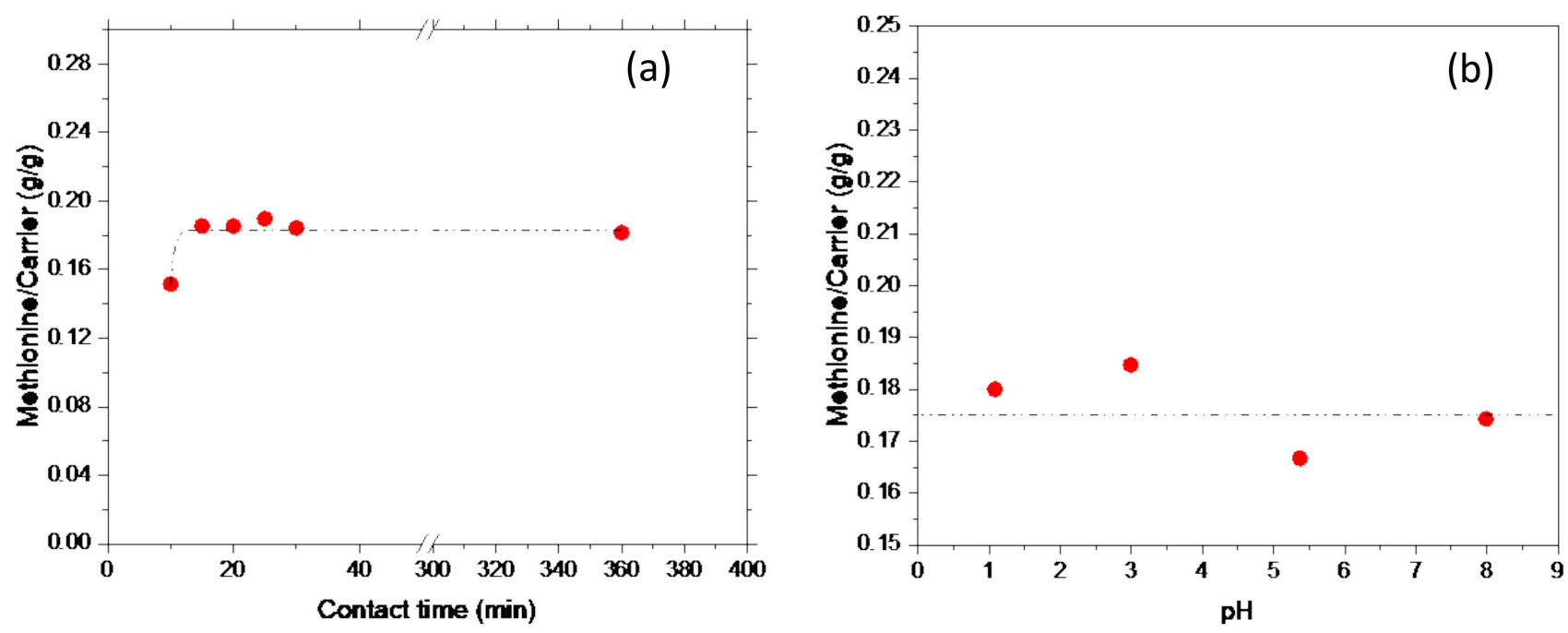

Figure 2. Methionine capture by Adsorbene ${ }^{\circledR}$ (a) at different contact time and (b) at different methionine solution pH.

As shown in Figure 2a, where captured methionine is reported as a function of contact time, a very fast reaction occurred; the equilibrium was reached in $15 \mathrm{~min}$ which corresponded to a constant methionine capture of $0.18 \mathrm{~g}$ MET $/ \mathrm{g}_{\mathrm{ADS}}$. Accordingly, to achieve the equilibrium conditions, all the experiments performed in this work were performed at 30 min of contact time.

Similarly, the influence of $\mathrm{pH}$ on methionine capture is plotted in Figure $2 \mathrm{~b}$. No $\mathrm{pH}$ effect was observed; indeed, a methionine capture of $0.18 \mathrm{~g}_{\mathrm{MET}} / \mathrm{g}_{\mathrm{ADS}}$, corresponding to the equilibrium and only depending on contact time, was observed. This result can be traced back to the reported buffer capacity of both the amino acids [35] and mineral clays [36].

The samples MET-ADS contacted at different $\mathrm{pH}$ were also analyzed by FTIR spectroscopy, which has been proven to be a useful technique in investigating structure and conformation of organic moieties in clay composites [26,37].

Pristine solid methionine is present as the zwitterionic form. Assignments of the main IR bands were determined from comparison with literature data. The diagnostic bands due to the $-\mathrm{NH}_{3}{ }^{+}$group are assigned as follows: $\mathrm{NH}$ stretching modes at 2725 and $2615 \mathrm{~cm}^{-1}$, with a component at $2100 \mathrm{~cm}^{-1}$ ca.; $\mathrm{NH}$ deformation mode at $1580 \mathrm{~cm}^{-1}$ with weaker components at 1515 and $1655 \mathrm{~cm}^{-1}$ (shoulder). Correspondingly, the $\mathrm{COO}^{-}$group is characterized by two bands at 1610-15 asymmetric stretching and $1415 \mathrm{~cm}^{-1}$ symmetric stretching. These features are mixed extensively with $-\mathrm{NH}_{3}{ }^{+}$bending vibrations that fall at similar frequencies [38-40].

The side chain of methionine molecules is reported to show two sharp characteristic bands due to $\mathrm{CH}$ deformation of the $\mathrm{S}-\mathrm{CH}_{3}$ group at 1445 and $1340 \mathrm{~cm}^{-1}$. Other deformation modes of $\mathrm{CH}$ in the side appear as weak and sharp bands below $1350 \mathrm{~cm}^{-1}$.

The $\mathrm{C}-\mathrm{S}$ stretching mode is reported at lower frequencies, showing two bands at 718 and $684 \mathrm{~cm}^{-1}$ [41].

In the spectra of the organoclays, bands belonging to methionine are very weak, as expected, therefore we report in Figure 3 the subtraction spectra [ADS + MET] - [ADS] in order to magnify the organic compound features. 


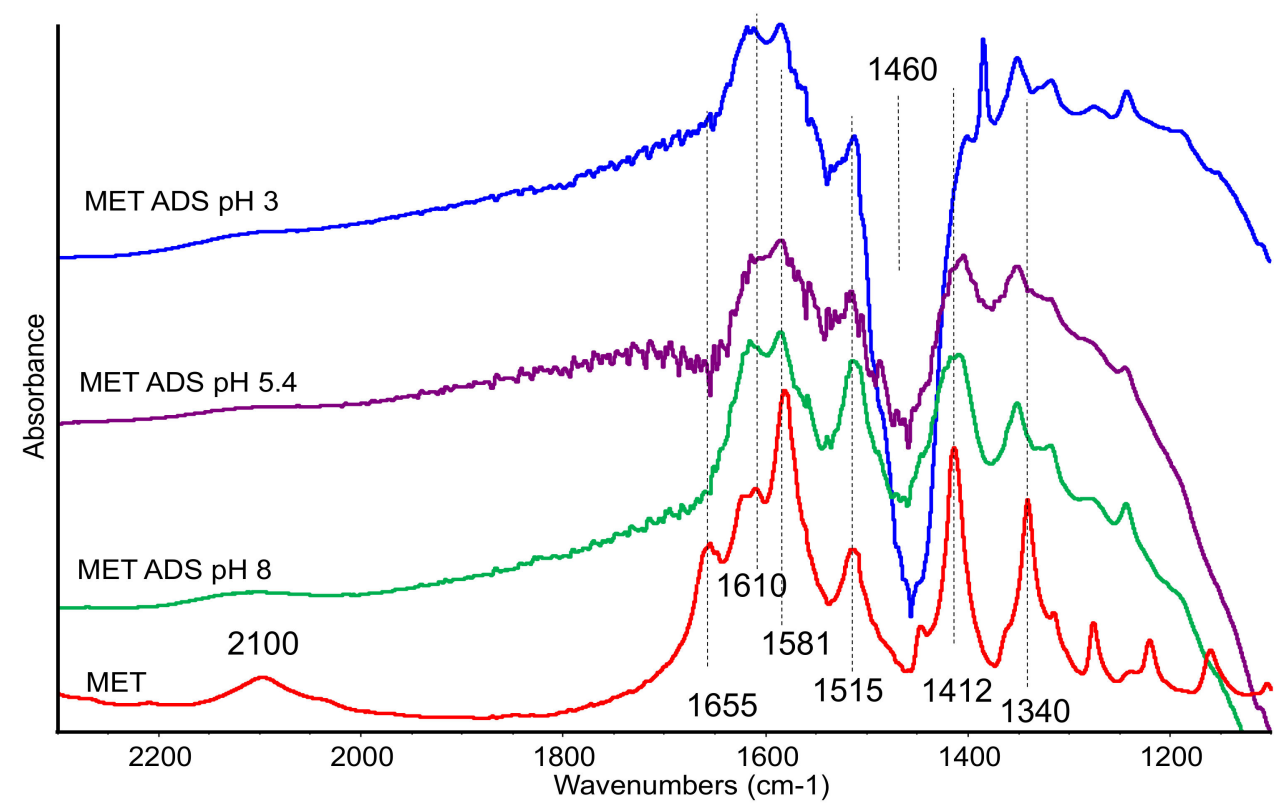

Figure 3. FTIR subtraction spectra (ADS + MET) - (ADS) at different $\mathrm{pH}$. Pure methionine spectrum is also reported as reference.

The spectra of the sample recorded after contacting at $\mathrm{pH} 1$ was dominated by a strong and sharp band at $1384 \mathrm{~cm}^{-1}$, assigned to residual nitrate species, and no other features were detected (spectrum not reported). In the spectra recorded on the samples treated at $\mathrm{pH} 3,5$, and 8 , few bands appeared in the low-frequency region, assigned to methionine and broadened by the interaction with the matrix. The presence of bands at $1620-1610 \mathrm{~cm}^{-1}\left(\operatorname{vasCOO}^{-}\right), 1585\left(\delta \mathrm{NH}_{3}{ }^{+}\right), 1510 \mathrm{~cm}^{-1}$, and $1415-10 \mathrm{~cm}^{-1}\left(v_{\mathrm{SCOO}}^{-}\right)$, still detectable although slightly broadened, evidenced the interaction of methionine in its zwitterionic form. The negative band at $1460 \mathrm{~cm}^{-1}$ was due to the residual organic compound, whose amount decreased after contact with methionine.

The disappearing of the band at $1655 \mathrm{~cm}^{-1}$ (detected also in the spectra of the mechanical mixture) and the reduced relative intensity of the band at $1585 \mathrm{~cm}^{-1}$, both of them assigned to $-\mathrm{NH}_{3}{ }^{+}$group, suggests that this group was mainly affected by the interaction with the clay. On the other side, acidic $\mathrm{pH}$ also did not significantly affect bands of carboxylate species still detectable in the spectra.

Bands at lower frequencies, namely at $1350 \mathrm{~cm}^{-1}$, due to the $\mathrm{CH}_{3}$ group, and at $728 \mathrm{~cm}^{-1}$, due to C-S stretching mode, were slightly shifted to higher frequencies in comparison with pure methionine, suggesting a limited perturbation of the side chain after interaction.

In sum, all the spectral features were actually very similar in the different spectra, thus changes in $\mathrm{pH}$ did not affect the nature of the interaction with the clay. The analysis of the IR spectra is consistent with a weak MET-ADS interaction that does not significantly change the methionine structure.

\subsection{Effect of Methionine Content in the Initial Solution}

The effect of initial methionine content is reported in Figure 4a. It was evident that all the carriers were able to capture the target molecule; however, in different extents and, apparently, via different mechanisms. VEG was able to adsorb larger amounts of methionine, but, at higher methionine content, a plateau is reached. On the other side, ADS and $\mathrm{BIO}$, which evidenced a fully overlapped linear behavior, were able to capture lower amounts of methionine, on average $1 / 3$ of VEG, but no site saturation was apparently present. To deeper comprehend differences in the intercalation/adsorption characteristics and the occurring mechanisms when the different sorbents are used, adsorption isotherms measurements were analyzed. The methionine-clay interaction was interpreted according 
to both Langmuir and Freundlich models [24,25]. It is well known, indeed, that the Langmuir model describes a more homogeneous distribution of adsorption sites energy, where equal active sites can be occupied only once, while the Freundlich model is able to describe complex and heterogeneous surfaces.
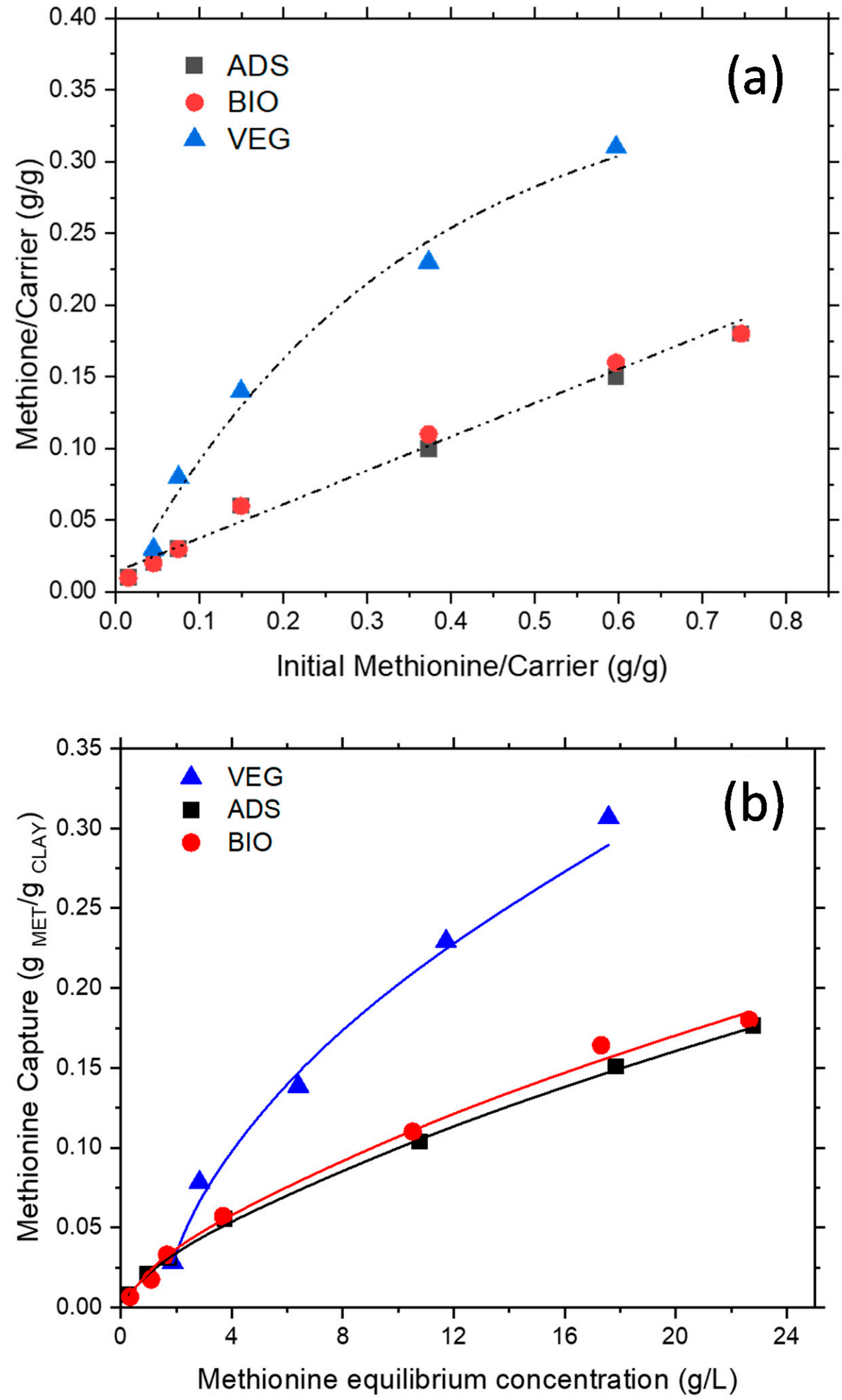

Figure 4. Cont. 


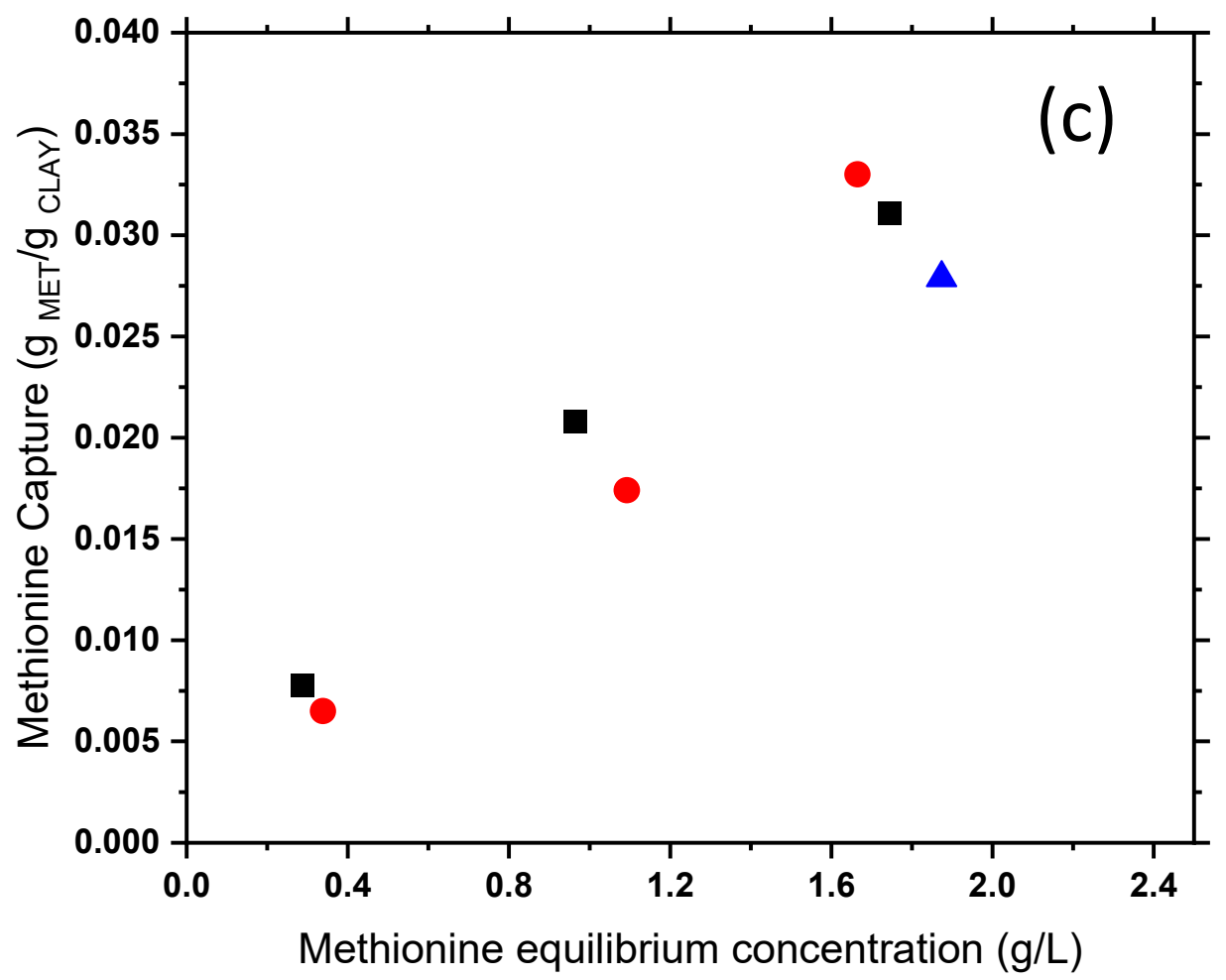

Figure 4. Comparison between (a) capture capabilities (open symbols: MET-ADS and MET-VEG washed once and twice); (b) adsorption isotherms (lines: Freundlich model); (c) isotherms in the $0-0.25 \mathrm{~g} / \mathrm{L}$ range of methionine equilibrium concentration.

For all the systems, the Freundlich model provided the best agreement with the experimental data (Figure $4 \mathrm{~b}$ ). Moreover, considering fitting results, it appears that for the MET-VEG system, higher values of both the adsorption capacity ( $\mathrm{K} \cong 0.068$ for VEG vs. $\mathrm{K} \cong 0.023$ for $\mathrm{ADS}$ or $\mathrm{BIO}$ ) and the heterogeneity factor $(\mathrm{n} \cong 1.9$ for VEG vs. $\mathrm{n} \cong 1.5$ for ADS or BIO) were found. As a result, saturation over VEG occurred faster than over ADS or BioKi; moreover, VEG capture appeared also to occur only above a threshold concentration of about $1.7 \mathrm{~g} / \mathrm{L}$ (Figure $4 \mathrm{c}$ ).

To obtain information on the strength of interaction between methionine and carriers, three selected samples (two for MET-VEG and one for MET-ADS), after capture, were washed once and twice, by subsequent resuspensions of the powders in $50 \mathrm{~mL}$ of demineralized water for $10 \mathrm{~min}$ at $25^{\circ} \mathrm{C}$, stirring rate at $600 \mathrm{rpm}$. After solid-liquid separation as usual, the methionine in the supernatant solution was analyzed by COD. VEG released almost up to $55 \%$ of the captured methionine, while ADS released less than $10 \%$, even though the washing conditions were the same as applied to VEG (Figure 4a, open triangles). Such methionine was probably weakly bounded on the surface and/or not intercalated in the montmorillonite interlayer. Conversely, no release was found in the case of the MET-ADS sample (Figure 4, open squares) and MET-BIO one (Figure 5, open circles, not visible being overlapped), pointing out a stronger MET-ADS interaction.

These tests can give only preliminary indications; however, it can be concluded that methionine was more strongly captured by ADS than by VEG, and this behavior may be due to the different nature and morphology of the constituent mineral substrate, i.e., zeolite-type and montmorillonite-type, respectively.

Further investigation on interaction strength in MET-ADS samples was carried out by combined thermal analysis (TG) and FTIR at increasing temperature, and data is discussed in Section 3.5. 


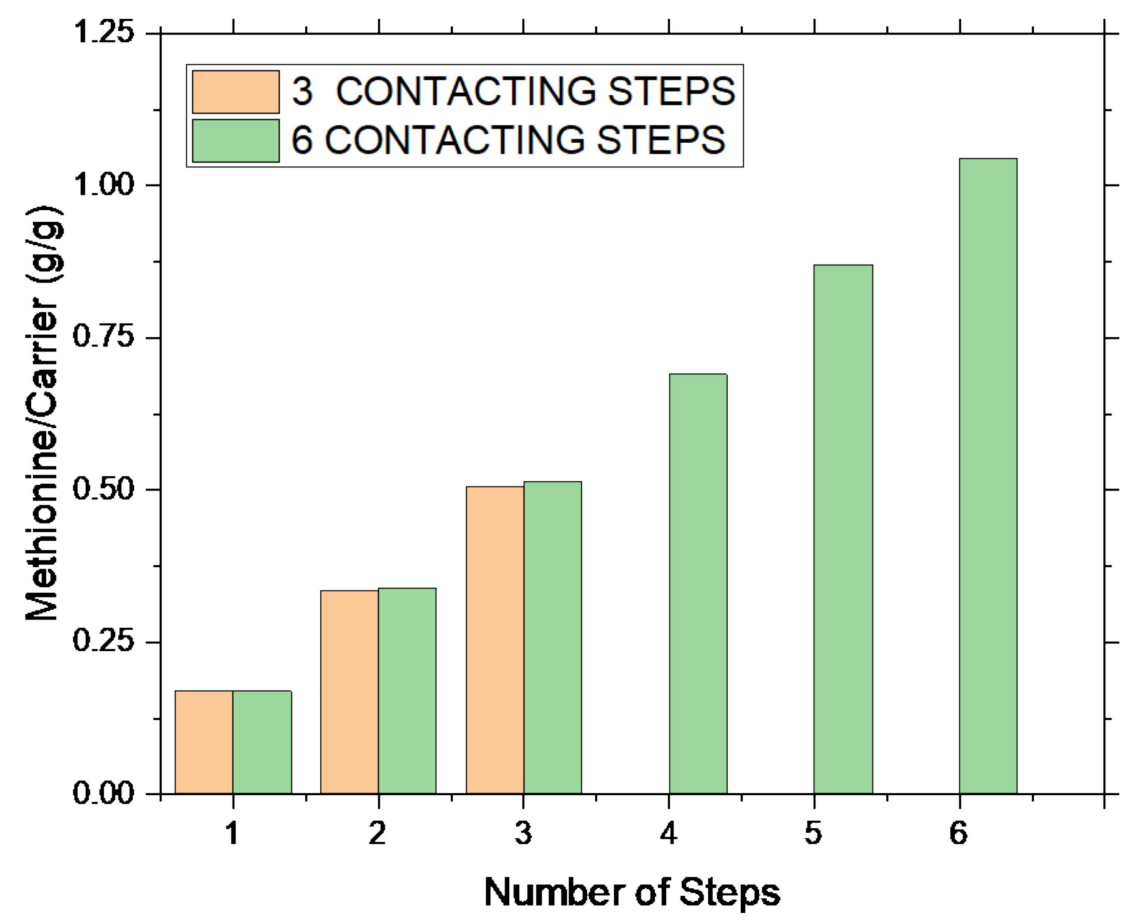

Figure 5. Methionine capture as a function of repeated three or six intercalation steps for the system MET-ADS.

Moreover, considering the release of methionine by washing observed for the METVEG system, this carrier was considered unsuitable for the target application; therefore, it was not further considered in the experimentation, except for comparison.

\subsection{Effect of Multiple Intercalation Steps}

On ADS, i.e., the carrier selected for the target application, multiple contacting experiments were also performed.

Each step was carried out with a fixed methionine concentration of $0.2 \mathrm{M}$, at room temperature and stirring at $600 \mathrm{rpm}$ for $30 \mathrm{~min}$. Upon liquid-solid separation, the liquid was analyzed by COD, while the solid by FTIR spectroscopy. In Figure 5, two sets of experiments, one considering three repeated intercalation steps, and another considering six intercalation steps, are plotted as a function of the steps number.

A constant amount of methionine is captured in each step (on average, $0.17-0.18 \mathrm{~g}$ of methionine for $\mathrm{g}$ of carrier). Considering experimental evidence (always the same amount of methionine is captured), in the case of the MET-ADS system, the adsorption process, apparently, does not depend on site availability, but rather on the methionine concentration in solution. Indeed, it appears that a threshold methionine value must be present in solution to act as a driving force of the adsorption reaction. A total methionine content of $0.51 \mathrm{~g}_{\mathrm{MET}} / \mathrm{g}_{\mathrm{ADS}}$ and $1.02 \mathrm{~g}_{\mathrm{MET}} / \mathrm{g}_{\mathrm{ADS}}$ was supported, respectively, upon three and six steps. The total captured methionine linearly increased with number of steps only, the MET/ADS ratio upon three steps being almost the half of the one upon six steps.

Similar results were also found for BIO, the reference zeolite material (not reported in the figure), where the same capture behavior was manifest, and a methionine capture of $0.50 \mathrm{~g}_{\mathrm{MET}} / \mathrm{g}_{\mathrm{BIO}}$ was measured after three steps. Accordingly, this behavior can be related to the surface area of these carriers, i.e., $93 \mathrm{~m}^{2} / \mathrm{g}$ for ADS and $103 \mathrm{~m}^{2} / \mathrm{g}$ for BIO, which in turn depends on the presence of a large zeolitic component (see Table 1 ).

Moreover, by comparing the three-step process (Figure 5, orange columns) with the first three steps of the six-step one (Figure 5, green columns), it can be concluded that the process is fully reproducible; once operating conditions and number of steps were fixed, the same amount of methionine was captured in two different experiments. 
Effect of the multiple intercalation steps was also studied by FTIR spectroscopy (Figure 6a,b).

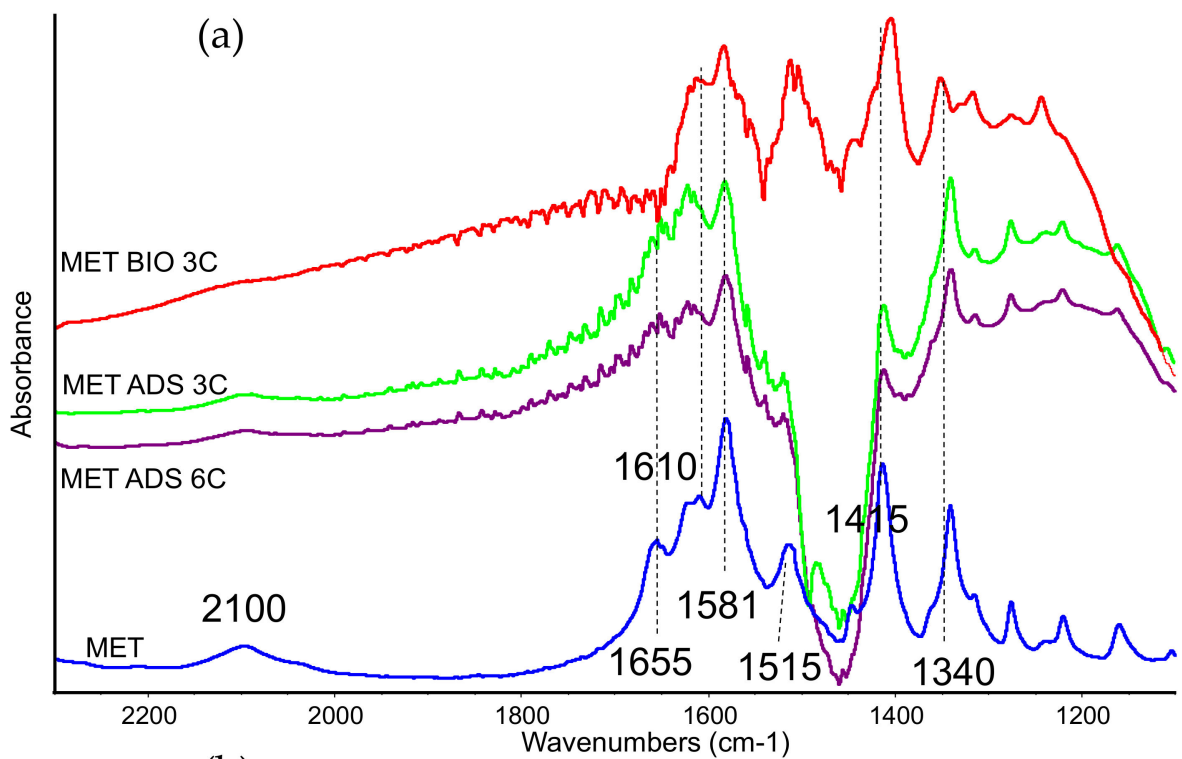

(b)

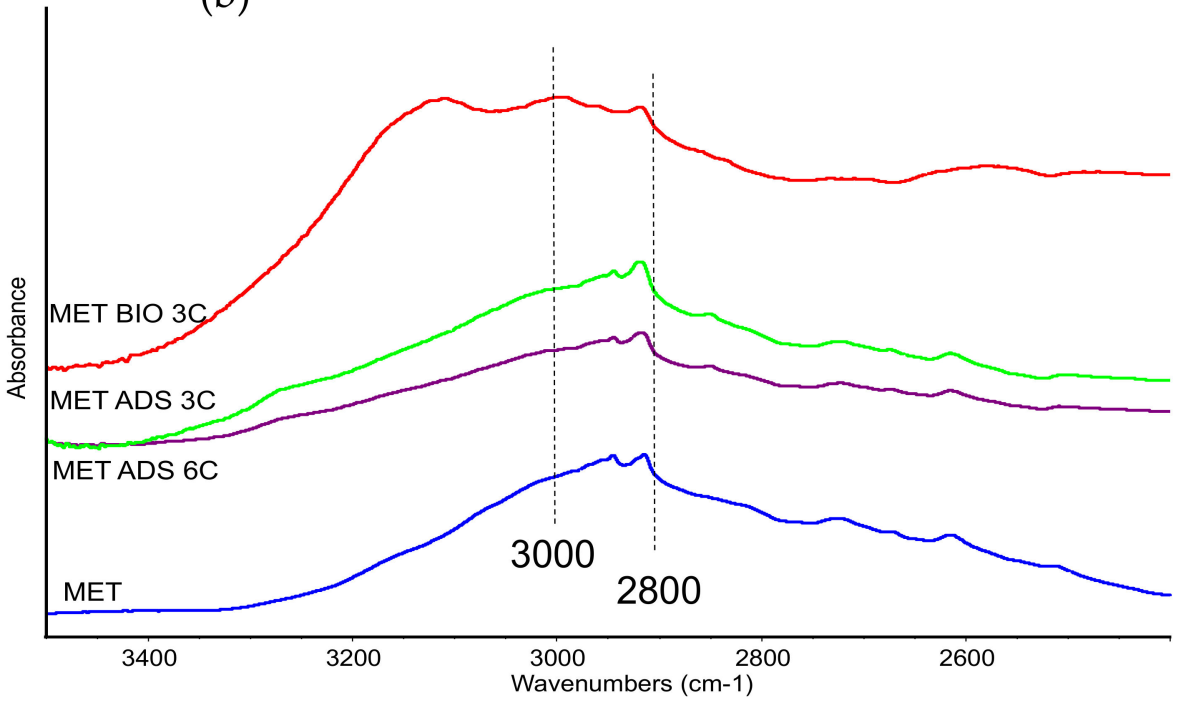

Figure 6. FTIR subtraction spectra (Adsorbene/BioKi + methionine) - (Adsorbene/BioKi) following multiple contacting tests: three steps and six steps. Pure methionine spectrum is also reported as reference: (a) low frequency region; (b) high-frequency region.

Over ADS, IR analysis evidenced, indeed, the presence of methionine, and multiple contacting resulted in an increased methionine-to-clay band intensity ratio (not-subtracted skeletal spectra are reported in Supporting S5), in agreement with data reported in Figure 5. As discussed previously, methionine is adsorbed in its zwitterionic form, as indicated by bands near $1655,1620,1580$, and $1415-10 \mathrm{~cm}^{-1}$, and by the weak absorptions above $2000 \mathrm{~cm}^{-1}$. Moreover, in the low-frequency region, some bands due to side chain of the amino acid are detected almost unchanged. The comparison with spectra previously reported seems to indicate that the molecule is even less affected by interaction with matrix. Possibly, more than one layers of methionine are deposited, loosening the interaction with clay surface and therefore leading to features close to the methionine solid compounds. Methionine adsorbed in the same conditions over BIO matrix showed IR bands that were slightly broadened and shifted (see, for instance, $\mathrm{CH}$ stretching bands in the range $3000-2800 \mathrm{~cm}^{-1}$, Figure $6 \mathrm{~b}$ ), evidencing a closer interaction with the host surface, in spite of multiple contacting runs. 


\subsection{Study of the Methionine-Carrier Interaction}

Organic molecule-mineral substrate interaction nature and strength can be deeper analyzed by combined TG-DTG and in situ FTIR analysis, as already reported in the literature for different organoclays [20,21].

Thermogravimetric analysis (Figure 7a-c) in air and in nitrogen (Supporting S6) were both performed on the solid phase of sample MET-ADS after three and six contacting steps (in the following, ADS 3C and ADS 6C). TG are reported in Figure 7a, while DTGs are reported in Figure 7b, where DTG of the pristine carrier and of a mechanical mixture of same composition of sample ADS 6C are plotted for comparison. DTG in air of pure methionine is plotted in Figure 7c.
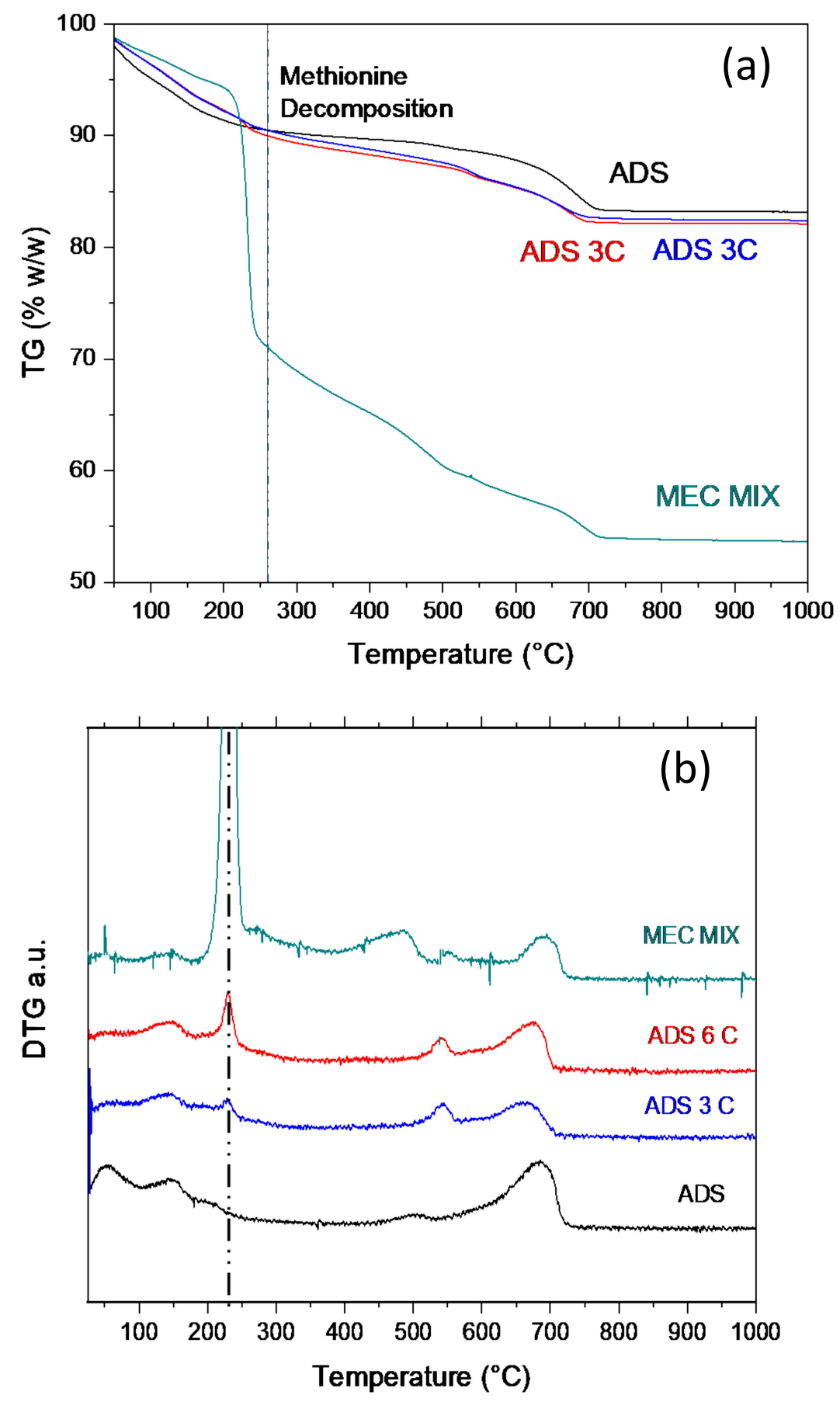

Figure 7. Cont. 


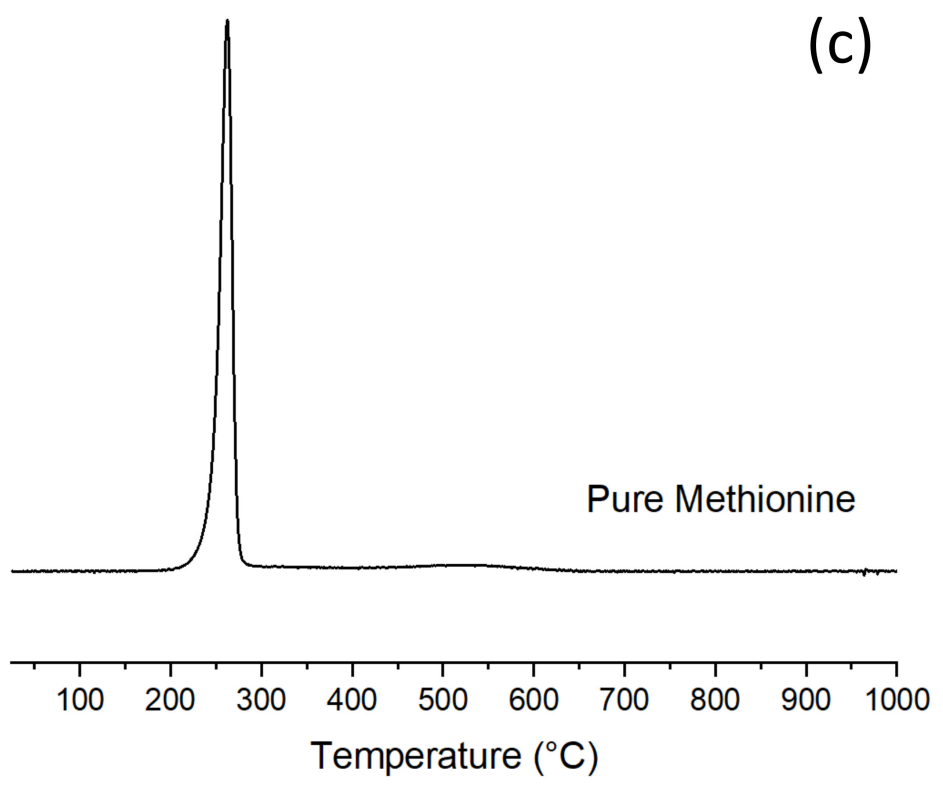

Figure 7. Thermogravimetric analysis in air of MET-ADS samples at three and six contacting steps: (a) TG, (b) DTG, (c) DTG of pure methionine. ADS and mechanical mixture reported for comparison.

In TG-DTG curves, different regions can be evidenced where different thermal phenomena occurred; analyzing it in detail it can be observed:

(1) A weight loss in the range $100-150{ }^{\circ} \mathrm{C}$ present in all the samples, but larger and more complex in pristine ADS, which is related to the release of water molecules allocated inside the clay interlayer and/or in the zeolite cages. Water evolution is lower in the case of the ADS 3C and 6C samples, as water molecules displacement occurred upon methionine intercalation [16]. Water evolution in the mechanical mixture is only barely evident due to the strong methionine decomposition.

(2) A weight loss in the range $220-240{ }^{\circ} \mathrm{C}$, always sharp and well defined, which is only present in the methionine-containing samples. This phenomenon is clearly associated with methionine decomposition, being centered at $250{ }^{\circ} \mathrm{C}$, and corresponding to pure methionine degradation. The extent of the phenomenon increases on increasing methionine content (Figure 7b, compare ADS 3C and ADS 6C). Considering temperature and shape, this phenomenon corresponds to free and/or weakly bounded methionine. This attribution is also confirmed by DTG of the mechanical mixture (Figure $7 \mathrm{~b}$ ) (composition equal to ADS 6C), where no and/or very poor MET-ADS interaction closely resembles pure methionine decomposition peak (Figure 7c).

(3) A weight loss in the range 500-550 ${ }^{\circ} \mathrm{C}$, evident in ADS 3C and ADS 6C, which can be attributed to the decomposition of methionine strongly interacting with the carrier, e.g., intercalated in the bentonite and/or trapped in the zeolite cages. The stronger interaction may displace the decomposition at higher temperature. Alternatively, this thermal phenomenon could correspond to the decomposition of residues formed during methionine decomposition and re-adsorbed onto the clay. This last hypothesis is apparently also consistent with the small and barely evident peak, at the same temperature, in DTG of the mechanical mixture.

(4) The broad peak centered at about $470{ }^{\circ} \mathrm{C}$, and clearly evident in both ADS and MEC MIX, can be due to decomposition of the organic molecules already present in the pristine clay.

The IR spectra of gas phase species at increasing temperatures for the same ADS 6C show the presence of bands in the $2400-2300 \mathrm{~cm}^{-1}$ region and in the $2160-2130 \mathrm{~cm}^{-1}$ one at the highest temperatures, consistent with the formation of $\mathrm{COx}$ from decomposition products from the organic molecules (both methionine and intercalated ammonium com- 
pound). In particular, bands in the $2400-2300 \mathrm{~cm}^{-1}$ region correspond to $\mathrm{CO}_{2}$ production, while the ones in the $2160-2100 \mathrm{~cm}^{-1}$ region are related to CO formation (Supporting S6).

$\mathrm{CO}$ formation starts at about $450{ }^{\circ} \mathrm{C}$, while $\mathrm{CO}_{2}$ formation starts at $490^{\circ} \mathrm{C}$, and this behavior is consistent with results from the thermogravimetric analysis described above, pointing out that captured methionine decomposes between $400{ }^{\circ} \mathrm{C}$ and $600^{\circ} \mathrm{C}$. No strongly adsorbed species are detected at the clay surface after this treatment.

As for thermogravimetric analysis in nitrogen atmosphere (not reported), all the weight losses were slightly translated towards higher temperature and were less pronounced, since oxidation reactions are less favored in inert conditions.

In case of $\mathrm{BIO} 3 \mathrm{C}$, i.e., the sample obtained by contacting the BioKi with the methionine solution three times, TG data showed that methionine decomposition (not reported) was fully overlapped and only a broad shoulder was evident, with a large water evolution phenomenon; thus, a certain assignment was not possible.

\subsection{MET-ADS Release after In Vitro Digestion Simulation}

Release of methionine from MET-ADS after in vitro digestion was assessed. After in vitro digestion, samples were taken and concentrations of methionine were analyzed by HPLC. Our study showed that the release of methionine occurs after digestion. Results are reported in Table 2. The release of methionine was observed in MET-ADS $2.5 \mathrm{mM}$ and MET $2.5 \mathrm{mM}$ samples (4.92 and 99.64, respectively).

Table 2. Methionine percentage quantified after in vitro digestion. Results are presented as percentage of the methionine initial dosage recovered (\%) after in vitro digestion.

\begin{tabular}{ccc}
\hline Sample & Sample Condition & $\begin{array}{c}\text { Percentage Recovered after } \\
\text { in vitro Digestion (\%) }\end{array}$ \\
\hline CTR & ADS alone pH 7 (no MET) & n.d. \\
MET-ADS 2.5 mM & ADS + 2.5 mM MET & $4.92 \pm 0.34$ \\
MET 2.5 mM & 2.5 mM MET & $99.64 \pm 11.98$ \\
\hline
\end{tabular}

\section{Discussion}

As demonstrated in the Results section, the experimental approach here adopted allowed for the effective capture of methionine on mineral substrates, namely Adsorbene, the bentonite-zeolite-based mixed material. By a single intercalation step, ADS is able to capture up to $0.18 \mathrm{~g}_{\mathrm{MET}} / \mathrm{g}_{\mathrm{ADS}}$, via a mechanism that is mainly related to methionine trapping inside the pores of the material. Adsorption mechanism is favored by the material morphology, characterized by the high surface area of $93 \mathrm{~m}^{2} / \mathrm{g}$, and it is confirmed by the occurrence of a very fast reaction, where equilibrium is reached within $15 \mathrm{~min}$. This picture is consistent with the phase composition of ADS that predominantly consists of zeolites rather than expandable clay components. Indeed, ADS morphology, composition, and behavior are very close, if not the same, to those of BIO, the selected reference for pure zeolite material (Table 1). The hypothesis that methionine is mainly captured by the zeolite component is also supported by the fact that both ADS and BIO, although slightly different in composition, are able to adsorb the same amount of methionine, and, once captured, the MET is not removed during washing. This occur due to a stronger interaction MET-carrier that can be attributed to the zeolite smaller porosity (dimeter $=3-4 \mathrm{~nm}$ ) of the zeolite component, and to a capture mechanism other than intercalation. Intercalation mechanism has been reported for montmorillonite-based clay, such as VEG, where organic molecules can be allocated in neutral form, inside the clay interlayer which is expandable [42], without ion exchange [24].

Such a capture mechanism results in a progressive site saturation, in view of a limitation of the interlayer expansion, as observed in the case of VEG, but not in the cases of ADS and BIO (Figure 4), where no saturation was observed. ADS and BIO can adsorb, for each single step, a lower amount of MET; however, although in greater quantities, the methionine adsorbed by VEG is only partially strongly interacting with the carrier, and 
almost $55 \%$ is weakly, or not, bonded with the carrier. The interaction is so weak that part of the adsorbate can be washed away by demineralized water. The system MET-VEG could be considered as a mechanical mixture of free methionine and MET-intercalated VEG. A situation different than a mechanical mixture was confirmed for the MET-VEG system, where the TG-DTG analysis evidenced that the MET-containing samples cannot be a simple mixture of the raw methionine and the raw Adsorbene (Figure 7). Indeed, the thermal decomposition of the organoclay samples is a complex multistep phenomenon, largely different than that of the single raw components. Thus, the presence of some MET-ADS interaction stronger than a simple surface interaction must be active. Once more, adsorption, via pore trapping, appears to be the mechanism of choice to explain MET-VEG interaction. To increase the methionine content, multiple adsorption steps can be performed; indeed, the methionine capture is a linear process, so that, by repeating the single step process six times on the same sample, the final adsorbed methionine was six-fold the one after a single step (Figure 5). Once the operating conditions are fixed, the adsorption process is fully reproducible, and the final methionine content in the sample can be managed by the number of steps.

Due to the buffer capacity of both the amino acids, in view of its zwitterionic nature, and the carrier, which is able to adsorb $\mathrm{H}^{+}$and $\mathrm{OH}^{-}$, no $\mathrm{pH}$ effect on the capture process is evident, and the same equilibrium values are reached between $\mathrm{pH} 1$ and 8 . This absence of $\mathrm{pH}$ effect is confirmed by the IR findings, where the spectral features of the samples at different $\mathrm{pH}$ are actually very similar. Therefore, $\mathrm{pH}$ does not affect either the nature of the interaction nor methionine structure.

Methionine is adsorbed in its natural form, i.e., neutral and unmodified, and the interaction with the carrier is manifest. This assumption is confirmed by both FTIR and TG-DTG measurements. Indeed, in the FTIR spectra of the MET-ADS spectrum, bands belonging to methionine, despite very weak, are always present and their broadening can be due to methionine interaction with the carrier. Methionine interacts with the carrier in its zwitterionic form. Moreover, the reduced relative intensity of the ammonium bands at $1585 \mathrm{~cm}^{-1}$, together with the disappearing of the band at $1655 \mathrm{~cm}^{-1}$, suggests that METcarrier interaction mainly affects the $-\mathrm{NH}_{3}{ }^{+}$group. The slight shift to higher frequencies of the bands of the $\mathrm{CH}_{3}$ group and of the $\mathrm{CS}$ group suggests a limited perturbation of the side chain after interaction, also.

Upon multiple contacting experiments, an increased methionine-to-clay band intensity ratio is observed, in line with an increased methionine content in the sample. In addition, in the case of the multiple contacting steps process, methionine is present in its zwitterionic form, while the side chain of the amino acid is detected almost unchanged. The comparison with spectra upon a single-step contacting process seems to indicate that, in the multiplestep one, the molecule is even less affected by interaction with the matrix. It can be assumed that, possibly, more than one layers of methionine are deposited, loosening the interaction with clay surface, and therefore leading to features close to the pristine methionine compound.

The presence of free or weakly bonded methionine on the MET-ADS samples is also supported by TG-DTG analysis, where the sharp weight loss in the range $220-240{ }^{\circ} \mathrm{C}$ corresponds to pure methionine degradation (Figure 7). The extent of the phenomenon increases upon increasing methionine content, in line with FTIR indication that suggests the presence of more than one layer of methionine characterized by a very weak interaction with clay surface. However, TG data also evidenced a weight loss at $500-550{ }^{\circ} \mathrm{C}$ that corresponds to the decomposition of methionine strongly interacting with the carrier, being intercalated in the bentonite and/or trapped in the zeolite cages. This thermal phenomenon is only present in the MET-ADS samples, and not in the mechanical mixture, thus supporting the presence of methionine molecules characterized by different interaction degree with the carrier. FTIR data on MET ADS C6 thermal evolution also shows gas phase $\mathrm{CO}_{\mathrm{x}}$ formation in the high-temperature range, in agreement with this picture. MET-ADS samples also demonstrated release of methionine after in vitro digestion simulation. This 
approach provided a suitable strategy to produce and characterize the molecules that can be generated during in vivo digestion. Thus, the final hydrolysate obtained represents the pool of molecules (e.g., amino acids and peptides) resembling those generated during the physiological digestion of MET-ADS. A weak release $(<5 \%)$ of methionine from MET-ADS was observed at the end of the procedure.

It is evident that the bioaccessibility of methionine from MET-ADS is low, at least lower than the reasonable requirement for feed application. Such a behavior is not thought to be due to the preparation procedure, but mainly related to the carrier structure and phase composition. Indeed, the large zeolite content of Adsorbene makes methionine prone to strong interactions with the molecules. This way, methionine trapped in the zeolites cages cannot be released in as mild conditions as those of the in vitro digestion. Further studies on methionine bioaccessibility and intestinal absorption from MET-ADS are required to verify the in vitro preliminary results reported here. However, despite the need for further analysis, our results pose the basis for the use of clay-protected amino acids in feed. Indeed, it is the authors' opinion that, by a proper selection of the clay carriers, the proposed synthetic approach and the obtained materials can allow for application, in in-field animal feed, of biomolecules protection by natural clay.

\section{Conclusions}

The new clay-based hybrid organic-inorganic materials proposed here are a starting point for the development and use of mineral clays as protective host for amino acids and biomolecules in general for feed application. In this respect, the use of natural carriers and the proposed milder, environmentally friendly process conditions fulfill the requirement of a safer and greener production process.

The preparation procedure reported here is simple, reproducible, and allows for the adsorption of considerable amounts of amino acid.

Although our results can be considered preliminary, they pinpoint the need for a proper selection of the clay host. The capture and the release properties of the final material are indeed driven by the carrier morphology. A good balance between capability to load large amounts of the hosted molecule and, at the same time, to release it when is needed is fundamental for success in the final application. As an example, large zeolite content can favor the capture of very large amount of methionine, but the trapping mechanism, typical of these structures, prevents a satisfactory release in mild, or better, physiological conditions. Once the proper carrier is selected, the preparation procedure guarantees the administration of the amino acid in the right form. Neither the structure of the inorganic matrix nor the amino acid structure was changed in the preparation process. Methionine was detected in its zwitterionic form, and it is only slightly affected by the interaction. Despite the low methionine release, observed after in vitro digestion, further studies on methionine bioaccessibility and intestinal absorption are required to optimize the application of natural clay in animal nutrition.

Supplementary Materials: The following are available online at https: / www.mdpi.com/article / 10.3390/app11125669/s1, Supporting S1: XRD patterns of the pristine carriers: (a) Adsorbene and BioKi and (b) Veegum, Supporting S2: Granulometric analysis of (a) Adsorbene, (b) BioKi, and (c) Veegum, Supporting S3: FTIR skeletal spectra of pristine carriers, Supporting S4: $\mathrm{pH}$ as a function of methionine concentration in pure methionine solution, Supporting S5: FTIR spectra of MET ADS samples and reference ADS after multiple contact tests (subtraction results are reported in the main text), Supporting S6: FTIR spectra of the gas phase following heating at increasing temperature of MET-ADS 6C sample.

Author Contributions: Conceptualization, C.C., E.F., and L.R.; methodology, C.G. and S.P.; formal analysis, M.B.; investigation, C.C., L.R., and E.F.; writing-original draft preparation, C.C., E.F., C.G., M.D., L.R., and M.B.; writing-review and editing, C.G., L.R., and E.F.; funding acquisition, C.C., L.R., and M.B. All authors have read and agreed to the published version of the manuscript. 
Funding: This work was carried out with the financial support of the FOODTECH project (ID 203370), (https://www.openinnovation.regione.lombardia.it/it/b/7189/progetto-foodtech) this project is co-funded by European Regional Development Fund (ERDF). The funders had no role in study design, data collection and analysis, decision to publish, or preparation of the manuscript.

Institutional Review Board Statement: Not applicable.

Informed Consent Statement: Not applicable.

Data Availability Statement: All data are available upon reasonable request from the corresponding authors.

Acknowledgments: Thanks to ProPhos s.r.l. (San Giovanni in Croce, CR, Italy) and to Ferraroni SpA (Bonemerse, CR, Italy) for the coordination of the project, and to Giancarlo Selmini (Ferraroni SpA) for the stimulating discussion.

Conflicts of Interest: The authors declare no conflict of interest. The funders had no role in the design of the study; in the collection, analyses, or interpretation of data; in the writing of the manuscript, or in the decision to publish the results.

\section{References}

1. Grossi, S.; Rossi, L.; De Marco, M.; Rossi, C.A.S. The Effect of Different Sources of Selenium Supplementation on the Meat Quality Traits of Young Charolaise Bulls during the Finishing Phase. Antioxidants 2021, 10, 596. [CrossRef] [PubMed]

2. Hejna, M.; Gottardo, D.; Baldi, A.; Dell'Orto, V.; Cheli, F.; Zaninelli, M.; Rossi, L. Review: Nutritional ecology of heavy metals. Animal 2018, 12, 2156-2170. [CrossRef]

3. Hejna, M.; Moscatelli, A.; Onelli, E.; Baldi, A.; Pilu, S.; Rossi, L. Evaluation of concentration of heavy metals in animal rearing system. Ital. J. Anim. Sci. 2019, 18, 1372-1384. [CrossRef]

4. Wang, H.; Long, W.; Chadwick, D.; Velthof, G.L.; Oenema, O.; Ma, W.; Wang, J.; Qin, W.; Hou, Y.; Zhang, F. Can dietary manipulations improve the productivity of pigs with lower environmental and economic cost? A global meta-analysis. Agric. Ecosyst. Environ. 2020, 289, 106748. [CrossRef]

5. Toledo, M.Z.; Stangaferro, M.L.; Gennari, R.S.; Barletta, R.V.; Perez, M.M.; Wijma, R.; Sitko, E.M.; Granados, G.; Masello, M.; Van Amburgh, M.E.; et al. Effects of feeding rumen-protected methionine pre- and postpartum in multiparous Holstein cows: Lactation performance and plasma amino acid concentrations. J. Dairy Sci. 2021. [CrossRef]

6. Remus, A.; Peres, F.M.; Hauschild, L.; Andretta, I.; Kipper, M.; Gobi, J.D.P.; Pomar, C. Exploratory study on the utilization of different dietary methionine sources and methionine to lysine ratio for growing-finishing pigs. Livest. Sci. 2015, 181, 96-102. [CrossRef]

7. Papas, A.; Sniffen, C.; Muscato, T. Effectiveness of Rumen-Protected Methionine for Delivering Methionine Postruminally in Dairy Cows. J. Dairy Sci. 1984, 67, 545-552. [CrossRef]

8. Neto, J.P.D.C.; Bezerra, L.R.; Da Silva, A.L.; De Moura, J.F.P.; Filho, J.M.P.; Filho, E.C.D.S.; Guedes, A.F.; Araújo, M.J.; Edvan, R.L.; Oliveira, R.L. Methionine microencapsulated with a carnauba (Copernicia prunifera) wax matrix for protection from degradation in the rumen. Livest. Sci. 2019, 228, 53-60. [CrossRef]

9. Slamova, R.; Trčková, M.; Vondruskova, H.; Zralý, Z.; Pavlik, I. Clay minerals in animal nutrition. Appl. Clay Sci. 2011, 51, 395-398. [CrossRef]

10. Slaný, M.; Jankovič, L'.; Madejová, J. Structural characterization of organo-montmorillonites prepared from a series of primary alkylamines salts: Mid-IR and near-IR study. Appl. Clay Sci. 2019, 176, 11-20. [CrossRef]

11. Magnoli, A.P.; Texeira, M.; Rosa, C.A.R.; Miazzo, R.D.; Cavaglieri, L.R.; Magnoli, C.E.; Dalcero, A.M.; Chiacchiera, S.M. Sodium bentonite and monensin under chronic aflatoxicosis in broiler chickens. Poult. Sci. 2011, 90, 352-357. [CrossRef]

12. Mun, D.; Lee, J.; Choe, J.; Kim, B.; Oh, S.; Song, M. Value of clay as a supplement to swine diets. Korean J. Agric. Sci. 2017, 44, 181-187.

13. Mallakpour, S.; Dinari, M. Preparation and characterization of new organoclays using natural amino acids and Cloisite $\mathrm{Na}^{+}$. Appl. Clay Sci. 2011, 51, 353-359. [CrossRef]

14. Mallakpour, S.; Dinari, M. Surface Treated Montmorillonite: Structural and Thermal Properties of Chiral Poly(AmideImide)/Organoclay Bionanocomposites Containing Natural Amino Acids. J. Inorg. Organomet. Polym. Mater. 2012, $22,929-937$. [CrossRef]

15. Mallakpour, S.; Dinari, M. Insertion of novel optically active poly(amide-imide) chains containing pyromellitoyl-bis-1phenylalanine linkages into the nanolayered silicates modified with 1-tyrosine through solution intercalation. Polymers 2011, 52, 2514-2523. [CrossRef]

16. Imanipoor, J.; Ghafelebashi, A.; Mohammadi, M.; Dinari, M.; Ehsani, M.R. Fast and effective adsorption of amoxicillin from aqueous solutions by L-methionine modified montmorillonite K10. Colloids Surfaces A Physicochem. Eng. Asp. 2021, 611, 125792. [CrossRef] 
17. Chu, Y.; Zhu, S.; Xia, M.; Wang, F.; Lei, W. Methionine-montmorillonite composite-A novel material for efficient adsorption of lead ions. Adv. Powder Technol. 2020, 31, 708-717. [CrossRef]

18. Zampori, L.; Stampino, P.G.; Cristiani, C.; Cazzola, P.; Dotelli, G. Intercalation of poly(ethylene-oxides) in montmorillonite: Tailor-made nanocontainers for drug delivery systems. Appl. Clay Sci. 2010, 50, 266-270. [CrossRef]

19. Finocchio, E.; Baccini, I.; Cristiani, C.; Dotelli, G.; Stampino, P.G.; Zampori, L. Hybrid Organo-Inorganic Clay with Nonionic Interlayers. Mid- and Near-IR Spectroscopic Studies. J. Phys. Chem. A 2011, 115, 7484-7493. [CrossRef]

20. Zampori, L.; Dotelli, G.; Stampino, P.G.; Cristiani, C.; Zorzi, F.; Finocchio, E. Thermal characterization of a montmorillonite, modified with polyethylene-glycols (PEG1500 and PEG4000), by in situ HT-XRD and FT IR: Formation of a high-temperature phase. Appl. Clay Sci. 2012, 59, 140-147. [CrossRef]

21. Finocchio, E.; Cristiani, C.; Dotelli, G.; Stampino, P.G.; Zampori, L. Thermal evolution of PEG-based and BRIJ-based hybrid organo-inorganic materials. FT-IR studies. Vib. Spectrosc. 2014, 71, 47-56. [CrossRef]

22. Iannicelli-Zubiani, E.M.; Cristiani, C.; Dotelli, G.; Stampino, P.G.; Pelosato, R.; Finocchio, E. Effect of pH in the synthesis of organo-clays for rare earths removal. Environ. Eng. Manag. J. 2017, 16, 1719-1727. [CrossRef]

23. Zampori, L.; Stampino, P.G.; Cristiani, C.; Dotelli, G.; Cazzola, P. Synthesis of organoclays using non-ionic surfactants: Effect of time, temperature and concentration. Appl. Clay Sci. 2010, 48, 97-102. [CrossRef]

24. Cristiani, C.; Iannicelli-Zubiani, E.M.; Dotelli, G.; Finocchio, E.; Stampino, P.G.; Licchelli, M. Polyamine-based organo-clays for polluted water treatment: Effect of polyamine structure and content. Polymers 2019, 11, 897. [CrossRef] [PubMed]

25. Donohue, M.; Aranovich, G. Classification of Gibbs adsorption isotherms. Adv. Colloid Interface Sci. 1998, 76, 137-152. [CrossRef]

26. Lagazzo, A.; Barberis, F.; Carbone, C.; Ramis, G.; Finocchio, E. Molecular level interactions in brushite-aminoacids composites. Mater. Sci. Eng. C 2017, 70, 721-727. [CrossRef]

27. Minekus, M.; Alminger, M.; Alvito, P.; Ballance, S.; Bohn, T.; Bourlieu, C.; Carriere, F.; Boutrou, R.; Corredig, M.; Dupont, D. A standardised static in vitro digestion method suitable for food-an international consensus. Food 2014, 5, 1113-1124.

28. Giromini, C.; Lovegrove, J.A.; Givens, D.I.; Rebucci, R.; Pinotti, L.; Maffioli, E.; Tedeschi, G.; Sundaram, T.S.; Baldi, A. In vitrodigested milk proteins: Evaluation of angiotensin-1-converting enzyme inhibitory and antioxidant activities, peptidomic profile, and mucin gene expression in HT29-MTX cells. J. Dairy Sci. 2019, 102, 10760-10771. [CrossRef] [PubMed]

29. Miralles, B.; Sanchón, J.; Sánchez-Rivera, L.; Martínez-Maqueda, D.; Le Gouar, Y.; Dupont, D.; Amigo, L.; Recio, I. Digestion of micellar casein in duodenum cannulated pigs. Correlation between in vitro simulated gastric digestion and in vivo data. Food Chem. 2021, 343, 128424. [CrossRef]

30. Panseri, S.; Arioli, F.; Biolatti, C.; Mosconi, G.; Pavlovic, R.; Chiesa, L.M. Detection of polyphosphates in seafood and its relevance toward food safety. Food Chem. 2020, 332, 127397. [CrossRef]

31. Madejová, J. FTIR techniques in clay mineral studies. Vib. Spectrosc. 2003, 31, 1-10. [CrossRef]

32. Hu, Z.; He, G.; Liu, Y.; Dong, C.; Wu, X.; Zhao, W. Effects of surfactant concentration on alkyl chain arrangements in dry and swollen organic montmorillonite. Appl. Clay Sci. 2013, 75, 134-140. [CrossRef]

33. Yilmaz, N.; Yapar, S. Adsorption properties of tetradecyl- and hexadecyl trimethylammonium bentonites. Appl. Clay Sci. 2004, 27, 223-228. [CrossRef]

34. Busca, G.; Resini, C. Vibrational Spectroscopy for the Analysis of Geological and Inorganic Materials. Encycl. Anal. Chem. 2006. [CrossRef]

35. Bhagavan, N.; Ha, C. Essentials of Medical Biochemistry, 2nd ed.; Academic Press: Cambridge, MA, USA, $2015 ;$ pp. $21-29$.

36. Cristiani, C.; Iannicelli-Zubiani, E.M.; Bellotto, M.; Dotelli, G.; Stampino, P.G.; Latorrata, S.; Ramis, G.; Finocchio, E. Capture Mechanism of La and Cu Ions in Mixed Solutions by Clay and Organoclay. Ind. Eng. Chem. Res. 2021, 60, 6803-6813. [CrossRef]

37. Madejová, J.; Jankovič, L'.; Slaný, M.; Hronský, V. Conformation heterogeneity of alkylammonium surfactants self-assembled on montmorillonite: Effect of head-group structure and temperature. Appl. Surf. Sci. 2020, 503, 144125. [CrossRef]

38. McAuliffe, C.A.; Quagliano, J.V.; Vallarino, L.M. Metal Complexes of the Amino Acid DL-Methionine. Inorg. Chem. 1966, 5, 1996-2003. [CrossRef]

39. Lin-Vien, D.; Colthup, N.B.; Fateley, W.G.; Grasselli, J.G. The Handbook of Infrared and Raman Characteristic Frequencies of Organic Molecules; Elsevier: Amsterdam, The Netherlands, 1991.

40. Cao, X.; Fischer, G. Conformational and Infrared Spectral Studies of 1-Methionine and Its N-Deuterated Isotopomer as Isolated Zwitterions. J. Phys. Chem. A 2002, 106, 41-50. [CrossRef]

41. Wolpert, M.; Hellwig, P. Infrared spectra and molar absorption coefficients of the 20 alpha amino acids in aqueous solutions in the spectral range from 1800 to $500 \mathrm{~cm}^{-1}$. Spectrochim. Acta Part A Mol. Biomol. Spectrosc. 2006, 64, 987-1001. [CrossRef]

42. Murray, H.H. Clay Sorbents-The Mineralogy, Processing, and Applications. Acta Geodyn. Geomater. 2005, 2, 127. 